\title{
Membangun Mental Kepemimpinan Anak Melalui Kecerdasan Linguistik
}

\author{
Yeni Elyanna \\ yenielyanna@gmail.com \\ STAK Terpadu Pesat
}

\begin{abstract}
Children are not adults in small form, but humans who because of their circumstances have not yet reached the level of adult growth and development. Children can be instructed and guided from an early age that they can show and deserve to be leaders like God has stated. Building children's leadership, the main thing that is expected to be developed is children's linguistic intelligence. In developing children's linguistic intelligence, it is important for parents and educators to always provide opportunities for children to learn their intelligence. Providing opportunities and trust in children indirectly forms a child's leadership mentality. The purpose of this study, so that parents and educators and readers know that in building children's leadership, language intelligence is the first thing that must be developed. This writing is done by means of library research. Literature research is qualitative research, moving at the analytical level and having an emic perspective, namely obtaining data not based on related facts or theoretical facts.
\end{abstract}

Keywords: Mentally, Child Leadership, linguistic intelligence

\begin{abstract}
Abstrak
Anak bukanlah orang dewasa dalam bentuk kecil, namun manusia yang karena keadaannya belum sampai pada tingkat pertumbuhan dan perkembangan yang dewasa. Anak dapat diberi petunjuk dan dibimbing sejak dini bahwa mereka bisa menunjukan dan layak menjadi pemimpin seperti yang Tuhan nyatakan. Membangun kepemimpinan anak, hal utama yang sangat diharapkan untuk dikembangkan yaitu kecerdasan linguistik anak. Dalam Mengembangkan kecerdasan lingustik anak, penting bagi orang tua maupun pendidik untuk selalu memberikan kesempatan pada anak untuk mempelajari kecerdasan yang dimilikinya. Memberikan kesempatan dan kepercayaan kepada anak secara tidak langsung sudah membentuk mental kepemimpian anak. Tujuan dari penelitian ini, agar orang tua dan pendidik serta pembaca mengetahui dalam membangun kepemimpinan anak, kecerdasan bahasa menjadi hal pertama yang harus dikembangkan. Penulisan ini dilakukan dengan Penelitian kepustakaan. Penelitian kepustakaan adalah penelitian kualitatif, bergerak pada tingkatan analitik dan bersifat perspectif emic, yakni mendapatkan data bukan berdasarkan fakta-fakta yang berhubungan maupun fakta secara teori.
\end{abstract}

Kata kunci : Mental, Kepemimpinan Anak, kecerdasan linguistik 
PENDAHULUAN

Pemimpin dan kepemimpinan merupakan seni dan keterampilan seseorang dalam menggunakan wewenangnya untuk berpengaruh bagi pengikut agar menjalankan kegiatan tertentu, yang diarahkan berdasarkan tujuan yang sudah ditentukan. ${ }^{1}$

Anak dapat dibimbing dan diberikan arahan sejak dini bahwa anak layak menjadi pemimpin dan mampu menunjukan kepemimpinannya seperti yang Tuhan nyatakan. Karena seorang anak mampu menggunakan 20\% ruang gerak dengan penuh kebaikan melalui berpikir benar, rasa benar dan juga tindakan yang benar. Seorang anak dibimbing mulai dari usia dini menjadi pemimpin untuk dirinya. ${ }^{2}$ Karena pada hakekatnya anak bukalah orang dewasa dalam bentuk kecil, namun manusia yang karena keadaannya belum sampai pada tingkat pertumbuhan dan perkembangan yang dewasa. ${ }^{3}$

\footnotetext{
1 Timotius, kepemimpinan dan kepengikutan teori \& perkembangannya, (Yogyakarta: CV Andi Offset, 2016), hal 18

${ }^{2}$ Ade E. Sumengkar, Good, Great, Beyond menjadi pribadi penuh kesadaran diri menuju akreditasi mandiri, (Yayasan Keluarga Haerhave : Cetakan 1, 2020), hal 17

${ }^{3}$ Suryanah, keperawatan anak untuk siswa SPK, (Jakarta: Buku Kedokteran BGC, 1996), hal 1
}

Prinsip dasar pengembangan kepemimpinan adalah organisasi hendaknya tidak pernah mempercayakan jabatan atau posisi kepemimpinan tim kepada individu yang tidak pernah mendapat pelatihan. ${ }^{4}$ Dalam membangun kepemimpinan anak hal utama yang sangat diharapkan untuk dikembangkan yaitu kecerdasan linguistik anak. Kecerdasan linguistik berarti cerdas kata, dan mudah menangkap kata-kata baik mendengar dan melihat. Orang tua dan pendidik harus mampu mengembangkan kepemimpinan anak melalui Kecerdasan lingusitik. Menurut Gardner dalam (Amstrong, 2002:7), kecerdasan linguistik "pecah" pada permulaan masa kanak-kanak dan selalu ada sampai anak menjadi dewasa. ${ }^{5}$ Kecerdasan ini mengharuskan kemampuan anak untuk menyerap macam-macam informasi yang berarti berhubungan dengan cara berpikirnya. ${ }^{6}$ Kecerdasan merupakan salah satu anugerah terbesar dari Tuhan kepada manusia dibandingkan dengan mahkluk lainnya. Dengan kecerdasannya, manusia dapat selalu mempertahankan dan meningkatkan nilai hidupnya yang semakin menyatu, dengan

\footnotetext{
${ }^{4}$ John Adair, cara menumbuhkan pemimpin 7 prinsip kunci pengembangan kepemimpinan yang efektif, (Jakarta: PT Gramedia Pustaka Utama, 2007), hal 79

${ }^{5}$ Khabib Sholeh, fathur Rokhman, Rustono, Zamzani, Kecerdasan majemuk berorientasi pada partisipasi peserta didik, (Yogyakarta: Pustaka Pelajar, 2016), hal 26-26.

${ }^{6}$ Ibid, hal 25
} 
cara berpikir dan belajar secara berkelanjutan. $^{7}$ Namun banyak orang dewasa yang beranggapan bahwa seorang anak cerdas, pintar itu hanya diukur dari kecerdasan berhitung atau berprestasi dibidang akademik saja. Ada beberapa kecerdasan yang harus diperhatikan oleh pendidik dan orang tua, serta yang perlu untuk dikembangkan. Salah satunya yaitu mengembangkan kecerdasan linguistik anak. Perkembangan zaman membuat anak bahkan orang dewasa kurang berkomunikasi sehingga perkembangan bahasa anak menjadi kurang efektif, karena anak merupakan individu yang sangat senang mengamati, melihat, mendengar serta menyerap setiap kata yang diucapkan oleh orang dewasa.

$$
\text { Dalam Mengembangkan }
$$

kecerdasan lingustik anak, penting bagi orang tua maupun pendidik untuk selalu memberikan kesempatan pada anak untuk mempelajari kecerdasan yang dimilikinya. Memberikan kesempatan dan kepercayaan kepada anak secara tidak langsung sudah membentuk mental kepemimpian anak. Meski tidak berkembang secara cepat, namun dapat berkembang dan terbangun seiring dengan pertumbuhan, perkembangan dan kesempatan yang terus dimanfaatkan.

${ }^{7}$ Ibid, hal 18 kecerdasan ini mencakup kemampuan untuk memanipulasi atau struktur bahasa, bunyi bahasa, sistematika atau makna bahasa, dan dimensi pragmatis atau penggunaan praktis bahasa. beberapa dari kegunaan ini termasuk retorika (menggunakan bahasa untuk mempengaruhi orang lain untuk mengambil tindakan tertentu), mnemonik (menggunakan informasi mengingat bahasa), penjelasan (menggunakan bahasa untuk menginformasikan), dan metalanguage (menggunakan bahasa untuk berbicara tentang dirinya sendiri). ${ }^{8}$ Faktor ini sangat berpengaruh bagi kepemimpinan anak, karena dalam Kepemimpinan bukan hanya berkaitan dengan otoritas. Kepemimpinan berbicara tentang kemampuan dan kesanggupan dari dalam diri seseorang untuk mempengaruhi orang lain, bekerja mencapai tujuan suatu oranganisasi yang sudah ditetapkan. ${ }^{9}$

Kecerdasan linguistik berarti cerdas kata, cerdas mengolah kata-kata, baik melalui pendengaran maupun dengan melihat. Dalam kecerdasan lingustik, memakai kata merupakan cara utama untuk memutuskan sesuatu dan mengakhiri suatu masalah. Seseorang dengan kecerdasan ini menggunakan kata-

\footnotetext{
${ }^{8}$ Thomas Armstrong, Multiple Intelligences in the classroom (ASCD, 2009) hal 6

${ }^{9}$ Suparman, Kepemimpinan kepala sekolah \& guru (sebuah pengantar teoritik). Uwais Inspirasi Indonesia: 2019) hal 19
} 
kata untuk meyakinkan, meminta, menentang, menyenangkan dan mengajar orang yang dipimpinnya. ${ }^{10}$ Ini yang menjadi alasan pentingnya dalam membangun mental kepemimpinan, seseorang harus memiliki kecerdasan lingustik yang baik, tepat dan benar.

\section{METODE PENELITIAN}

Metode penelitian pada hakikatnya merupakan cara keilmuan untuk mendapatkan data dengan tujuan dan kegunaan tertentu. Berdasarkan hal tersebut terdapat empat kunci yang perlu diperhatikan yaitu pertimbangan yang logis, berdasarkan pengalaman dan teratur. ${ }^{11}$

Penulisan ini menggunakan metode kepustakaan. Zed (2004) memandang bahan pustaka terbatas oleh ruang dan waktu. Namun, penulis menginterprestasi makna sebuah teks atau wacana bukan suatu pekerjaan yang mudah, tidak hanya yang tersirat, tetapi yang tersurat, bukan hanya yang tampak tetapi yang tidak tampak. Menurut Furchan dan Maimun (2005) penelitian kepustakaan berada pada kuadran empat tingka. Karenanya

\footnotetext{
${ }^{10}$ Fildzah Imami, Strategi pembelajaran Anak Usia Dini Brbasis Multiple Intelligences, (Jawa tengah: Mangku Bumi, 2018) hal 1

${ }^{11}$ Sugiyono, metode penelitian kuantitatif, kualitatif dan R\&D, (Bandung:Alfabeta, 2016) hal 2
}

penelitian kepustakaan bukan aktivitas yang pasif, statis dan bias seperti yang disampaikan oleh Zed (2004).

Secara umum penelitian dibagi menjadi tiga, yaitu 1) bersifat penemuan, jika data yang diperoleh dari penelitian merupakan data-data yang baru dan belum pernah diketahui. 2) bersifat pembuktian, jika data yang diperoleh dari penelitian digunakan untuk membuktikan adanya keraguan terhadap pengetahuan tertentu dan 3) bersifat pengembangan, jika data yang diperoleh digunakan untuk memperdalam dan memperoleh pengetahuan yang telah ada. Penelitian kepustakaan adalah penelitian kualitatif, bekerja pada tataran analitik dan bersifat perspectif emic, yakni memperoleh data bukan berdasarkan fakta-fakta konseptual maupun fakta teoritis. ${ }^{12}$

\section{PEMBAHASAN}

Kepemimpinan adalah kekuasaan atau kesanggupan yang digunakan oleh pemimpin untuk memobilisasi para pengikutnya untuk meraih visi atau tujuan organisasi. $^{13}$ Kepemimpinan adalah kemampuan yang di pakai oleh seorang

\footnotetext{
${ }^{12}$ Amir Hamzah, Metode Penelitian Kepustakaan library research, kajian Filosofis, Aplikasi, proses dan hasil penelitian, (Malang: Literasi Nusantara, 2020) hal 8-9

${ }^{13}$ Timotius, Op.Cit hal 15
} 
pemimpin dalam menggerakkan kepemimpinannya agar mampu mencapai tujuan yang telah ditetapkan.

Menurut Joseph C. Rosi (2004), kepemimpinan adalah suatu relasi yang saling berpengaruh antara pemimpin dan pengikut yang mengharapkanperalihan nyata yang menggambarkan tujuan bersama. Menurut Koontz \& O’Donnel (1989), kepemimpinan sebagai proses mempengaruhi pengikut sehingga mau bekerja dengan benar untuk mencapai tujuan organisasinya. ${ }^{14}$ Menurut Moejiono (2002), kepemimpinan adalah kesanggupan dalam memberikan pengaruh pergi kesatu arah yang sama karena pemimpin harus mempunyai beberapa kualitas kemampuan tertentu yang menjadikannya berbeda dengan pimpinannya. ${ }^{15}$

Menurut Kartini Kartono (1995:81) dalam Suradji dan Engelbetus Martono telah merumuskan fungsi kepemimpinan cukup panjang yakni mecocokkan, menunjukan, mengarahkan, membangun pengikut atau motivasi-motivasi kerja, menggerakkan organisasi, menmbangun jaringan-jaringan komunikasi yang baik, memberikan bimbingan yang efisien dan membawa para pengikut kepada sasaran

\footnotetext{
${ }^{14} Z a i n u d d i n$ Mustapa, Maryadi, Kepemimpinan Pelayan: dimensi baru dalam kepemimpinan, (Celebes Media Perkasa), hal 46-47

${ }^{15}$ Suparman, Op.Cit hal 12
}

yang ingin capai sesuai dengan kesepakatan waktu dan rancangan. (Suradji, et al., 2014 p. 66.

Berdasarkan uraian di atas, dapat simpulkan bahwa kepemimpinan adalah kemampuan pemimpin memobilisasi, berpengaruh atau mempengaruhi, membangun relasi bagi pengikutnya untuk mencapai visi atau tujuan dan pergi kesatu arah yang telah ditetapkan sesuai dengan kesepakatan waktu dan rancangan antara pemimpin dan pimpinan.

Kecerdasan linguistik adalah berhubungan erat dengan kata-kata, baik ungkapan secara langsung maupun tertulis beserta dengan peraturannya. ${ }^{16}$ Kecerdasan linguistik merupakan kecerdasan yang meliputi kemampuan berbahasa yang diucapkan dan yang tertulis untuk mengungkapkan diri atau mengingat berbagai hal. ${ }^{17}$ Menurut Howard Gadner kecerdasan linguistik adalah kemampuan untuk menggunakan kata-kata secara ucapan maupun tertulis. ${ }^{18}$ Kecerdasan verbal-linguistik merupakan kecerdasan dalam menggunakan bahasa dan kata-kata, baik secara verbal maupun non verbal.

\footnotetext{
${ }^{16}$ Khabib Sholeh, fathur Rokhman, Rustono, Zamzani, ibid, hal 25

${ }^{17}$ Gede sedana Suci, Hadian Wijoyo, Irjus Indrawan, Putu Gelgel, pengantar sosiologi pendidikan, (Jawa Timur: Qiara Media, 2020, hal 42-43 ${ }^{18}$ Widianto Setiono, Apakah Anda ingin menemukan potensi unggul anak Anda sejak dini?, (Grasindo), hal 18
} 
Anak-anak dalam kecerdasan jenis ini mempunyai skill mendengarkan sangat baik dan merupakan orang-orang cakap berbicara dengan baik dan benar. ${ }^{19}$

Berdasarkan uraian di atas dapat simpulkan bahwa kecerdasan linguistik adalah kecerdasan yang berhubungan dengan kata-kata baik yang diungkapkan secara ucapan maupun tulisan berserta dengan peraturannya. Anak-anak dalam kecerdasan ini juga mempunyai kemampuan mendengarkan dengan sangat baik dan mudah untuk menangkap berbagai infomasi serta dapat mengungkapkannya dengan baik dan benar.

\section{Membangun mental kepemimpinan anak melalui kecerdasan linguistik}

Menumbuhkan jiwa kepemimpinan anak tidak dapat dengan cara yang mudah, cepat dan tepat, melainkan memerlukan proses yang panjang, dari itu sangat penting membangun kepemimpinan anak sejak usia dini. Cara menumbuhkan Soft Skill pada diri anak : a) belajar serta bermain b) bersosialisasi dengan oranglain c) membentuk kelompok bermain d)

\footnotetext{
${ }^{19}$ Tisna Umi Hanifah, “Pemanfaatan media pop-up berbasis tematik untuk meningkatkan kecerdasan verbal-linguistik anak usia 4-5 tahun (studi eksperiman di TK Negeri pembina bulu Temanggung", BELIA: Early Education Papers 3 (2) 2014: November 2014, https://journal.unnes.ac.id/sju/index.php/belia/art icle/view/3727.
}

membiasakan diri dekat dengan Tuhan dengan berdoa. Soft skill menyumbangkan 85-90\% kesuksesan anak (Depdiknas, RI 1999). Menumbuhkan jiwa kepemimpinan pada anak akan melatih anak menjadi individu yang dapat dipercaya, mandiri dan berani. Mulai dari memimpin diri sendiri terlebih dahulu kemudian siap untuk memimpin orang lain. ${ }^{20}$ Mengasah jwa kepemimpinan anak sejak dini, bertujuan untuk mempersiapkan generasigenerasi penerus yang baik di waktu mendatang. Generasi yang siap untuk menghadapi tantangan dimasa mendatang. ${ }^{21}$

Strategi yang dapat digunakan dalam membangun kepemimpinan anak melalui kecerdasan linguistik yaitu : (1) Memberikan kesempatan kepada anak untuk bercerita, baik pengalaman saat di sekolah, di rumah maupun saat bermain. (2) lakukan sesi tanya jawab agar anak dapat menyampaikan kegiatan yang dilakukan. $^{22}$ (3) memberi kepercayaan kepada anak dengan memberikan

\footnotetext{
${ }^{20}$ Jubilee Enterprise, Lely, Rahasia para miliuner mendidik anak, (Elex Media Komputindo, 2014) hal 80

${ }^{21}$ Roni Rodiyana, Wina Dwi Puspitasari, "Menumbuhkan kepemimpinan anak di Sekolah Dasar". Jurnal Cakrawala Pendes 5 (2): 2019. http://dx.doi.org/10.31949/jcp.v512.1442
22 Munif Chatib, Alamsyah Said, sekolah anak-anak juara berbasis kecerdasan jamak dan Pendidikan berkeadilan, (Yogyakarta: Mizan Pustaka, 2012), hal 82


kesempatan anak untuk mengambil suatu keputusan. Kesempatan yang dipercayakan kepada anak dapat membantu anak untuk menunjukan bahwa dirinya dapat di percaya, sehingga dapat bertindak secara pelan dalam mengambil keputusan. (4) berfokus kepada kebutuhan anak dan jangan bersikap memaksa anak, karena memaksa sama dengan mengambil bagian anak, untuk bertumbuh dan berkembang sesuai dengan tahapan serta minat dan bakat anak. (5) memberikan pujian. Pujian diberikan ketika anak berhasil menyelesaikan tugas yang dipercayakan serta jangan memarahi atau membentak anak ketika melakukan kesalahan, karena secara tidak langsung hal ini bisa mematikan rasa percaya diri anak 23

Tujuan mengembangkan kecerdasan linguistik yaitu : (a) agar anak dapat berbicara/berelasi secara langsung maupun tertulis (b) mempunyai kemampuan bahasa yang mampu meyakinkan oranglain (c) dapat memikirkan dan menghafal informasi (d) dapat menyampaikan penjelasan (e) dapat menuangkan dengan bahasa sederhana. ${ }^{24}$

\footnotetext{
${ }^{23}$ Sri Lestari, Psikologi Keluarga penanaman nilai dan penanganan konflik dalam keluarga, (Jakarta: kencana, 2012), hal 204

${ }^{24}$ Arrofa Acesta, kecerdasan kinestetik dan interpersonal serta pengembangannya, (Surabaya: Media Sahabat Cendikia Pondok Maritim Indah: 2019), hal 17
}

\section{KESIMPULAN}

Menumbuhkan jiwa kepemimpinan anak tidak didapat dengan cara yang mudah, cepat dan tepat, melainkan memerlukan proses yang panjang, dari itu sangat penting membangun kepemimpinan anak sejak usia dini. Peran orangtua dan pendidik menjadi sangat penting untuk memperhatikan kebutuhan, melihat keunggulan dan kecerdasan masingmasing anak. Dalam membangun kepemimpinan anak hal utama yang sangat diharapkan untuk dikembangkan yaitu kecerdasan linguistik anak. Orangtua dan pendidik harus mampu mengembangkan kepemimpinan anak melalui Kecerdasan lingusitik. Setiap harinya anak akan berelasi dengan lingkungan sekitarnya dan akan banyak berkomunikasi. Jadi kecerdasan linguistik sangat mempengaruhi mental/jwa kepemimpinan anak sejak dini. 


\section{Daftar pustaka}

Timotius. 2016. kepemimpinan dan kepengikutan teori \& perkembangannya. Yogyakarta: CV Andi Offset.

Armstrong Thomas. 2009. Multiple Intelligences in the classroom. ASCD

Sumengkar E. Ade. 2020. Good, Great, Beyond menjadi pribadi penuh kesadaran diri menuju akreditasi mandiri. Yayasan Keluarga Haerhave

SholehKhabib, Rokhman fathur, Rustono, Zamzani. 2016. Kecerdasan majemuk berorientasi pada partisipasi peserta didik. Yogyakarta: Pustaka Pelajar.

Acesta Arrofa.2019. kecerdasan kinestetik dan interpersonal serta pengembangannya. Surabaya:Media Sahabat Cendikia Pondok Maritim Indah

Mustapa Zainuddin, Maryadi. Kepemimpinan Pelayan: dimensi baru dalam kepemimpinan, Celebes Media Perkasa.

Suparman,2019. Kepemimpinan kepala sekolah \& guru (sebuah pengantar teoritik), Uwais Inspirasi Indonesia.

Suci S. Gede, Wijoyo Hadian,Indrawan Irjus, Gelgel Putu, 2020. pengantar sosiologi pendidikan, Jawa Timur: Qiara Media.

Setiono Widianto Apakah Anda ingin menemukan potensi unggul anak Anda sejak dini?. Grasindo

Hanifah Umi Tisna, "Pemanfaatan media pop-up berbasis tematik untuk meningkatkan kecerdasan verbal-linguistik anak usia 4-5 tahun (studi eksperiman di TK Negeri pembina bulu Temanggung", BELIA: Early Education Papers 3 (2) 2014: November 2014, https://journal.unnes.ac.id/sju/index.php/belia/ article/view/3727.
Sugiyono, 2016. metode penelitian kuantitatif, kualitatif dan $R \& D$. Bandung:Alfabeta,

Hamzah Amir, 2020. Metode Penelitian Kepustakaan library research, kajian Filosofis, Aplikasi, proses dan hasil penelitian. Malang: Literasi Nusantara

Enterprise Jubilee, Lely, 2014. Rahasia para miliuner mendidik anak. Elex Media Komputindo: 2014

Adair John, 2007. cara menumbuhkan pemimpin 7 prinsip kunci pengembangan kepemimpinan yang efektif. Jakarta: PT Gramedia Pustaka Utama

Roni Rodiyana, Wina Dwi Puspitasari, "Menumbuhkan kepemimpinan anak di Sekolah Dasar". Jurnal Cakrawala Pendes 5 (2): 2019. http://dx.doi.org/10.31949/jcp.v512.1442

Sri Lestari.2012. Psikologi Keluarga penanaman nilai dan penanganan konflik dalam keluarga, Jakarta: kencana.

Chatib Munif, Said Alamsyah. 2012. sekolah anak-anak juara berbasis kecerdasan jamak dan Pendidikan berkeadilan, Yogyakarta: Mizan Pustaka. 